\title{
Synthesis and Characterisation of Various Diester and Triester Adducts of $\mathrm{TiCl}_{4}$
}

\author{
Ben J. Blackburn, Jared H. Crane, Caroline E. Knapp, Peter Marchand, David Pugh, Ivan P. Parkin, \\ Claire J. Carmalt* \\ Materials Chemistry Centre, Department of Chemistry, University College London, 20 Gordon Street, London, WC1H 0AJ, UK \\ Department of Chemistry, University of Southampton, Highfield, Southampton, SO17 1BJ, UK
}

\begin{abstract}
Titanium (IV) chloride and the triester glycerol tribenzoate (gtb) were reacted under moisture free conditions in order to investigate the use of triester-containing oils in the purification of $\mathrm{TiCl}_{4}$ in industrial processes. This resulted in the isolation of a chlorobridged dimeric complex containing four titanium centres $\left[\left\{\left(\mathrm{TiCl}_{4}\right)_{2}(\mathrm{gtb})\right\}_{2}\right](\mathbf{1})$. Further novel coordination compounds of $\mathrm{TiCl}_{4}$ and the diesters; bis-isopropyl malonate, dibenzyl malonate and diethyl succinate were synthesised by direct reaction under moisture free conditions, yielding [ $\left.\mathrm{TiCl}_{4}\left\{\mathrm{CH}_{2}(\mathrm{COO} P r)_{2}\right\}\right](2)$, [ $\left.\mathrm{TiCl}_{4}\left\{\mathrm{CH}_{2}\left(\mathrm{COOCH}_{2} \mathrm{Ph}\right)_{2}\right\}\right](3)$ and $\left[\mathrm{TiCl}_{4}\left\{\mathrm{C}_{2} \mathrm{H}_{4}(\mathrm{COOEt})_{2}\right\}\right]$ (4) respectively. The structures of compounds 1-4 were determined by single crystal X-ray diffraction. All structures assumed an octahedral geometry consisting of the titanium bound to four chloride ligands and the diester molecule acting as a bidentate ligand, through its two carbonyl oxygen atoms. Exposure of the isopropyl malonate reaction to trace amounts of water during synthesis resulted in the formation of an oxo-bridged dimeric structure $\left.\left[\mathrm{Ti}_{2}(\mu-\mathrm{O}) \mathrm{Cl}_{3}\left\{\mathrm{CH}_{2}(\mathrm{COO} \mathrm{Pr})_{2}\right\}_{2}\right)\right](\mathbf{2 b})$, the structure of which was also obtained via single crystal X-ray diffraction.
\end{abstract}

\section{Introduction}

Titanium dioxide $\left(\mathrm{TiO}_{2}\right)$ has a refractive index of 2.73 for the rutile phase and 2.55 for the anatase phase. ${ }^{[1]}$ This makes it the 'whitest pigment' available. ${ }^{[2]}$ In comparison zinc oxide has a refractive index of $2.00 .{ }^{[3]}$ Therefore, $\mathrm{TiO}_{2}$ is widely used as a whitening agent in paints, plastics and paper. ${ }^{[4]}$ Over 4.5 million tonnes are produced annually. $\mathrm{TiO}_{2}$ is largely obtained through mining and purification of ores such as rutile, anatase and ilmenite. All of these contain oxides of metals such as iron, aluminium, silicon and vanadium. [5] These oxides must be removed as thoroughly as possible in order to make the $\mathrm{TiO}_{2}$ fit for sale.

The ore is commonly purified using the chloride process. ${ }^{[6]}$ This involves reaction of the ore in a fluid bed with chlorine gas, converting the raw $\mathrm{TiO}_{2}$ that contains significant impurities into $\mathrm{TiCl}_{4}$. All other contaminants $\left(\mathrm{Fe}_{2} \mathrm{O}_{3}, \mathrm{~V}_{2} \mathrm{O}_{5}\right.$, $\mathrm{Al}_{2} \mathrm{O}_{3}$ ) present are also chlorinated and are then removed using a series of techniques before the purified $\mathrm{TiCl}_{4}$ is converted back to $\mathrm{TiO}_{2}{ }^{[7]}$ The difficulty of removing the other metal chloride impurities relates to their boiling points: any vanadium pentoxide present is converted to vanadium oxytrichloride $\left(\mathrm{VOCl}_{3}\right)$, which has a similar boiling point to $\mathrm{TiCl}_{4},\left(126{ }^{\circ} \mathrm{C}\right.$ and $136{ }^{\circ} \mathrm{C}$ respectively) and is difficult to remove via industrial scale distillation. ${ }^{[8]} \mathrm{VOCl}_{3}$ is traditionally removed by the addition of mineral oils, the components of which is a triglyceride backbone and unsaturated carbon chains of lengths $\mathrm{C} 15-18$ (Fig. 1). ${ }^{[9]}$ Although this process has been used for decades, little is understood about why the oil preferentially reacts with the $\mathrm{VOCl}_{3}$ rather than the $\mathrm{TiCl}_{4}{ }^{[10]}$ When mineral oil is added to liquid $\mathrm{TiCl}_{4}$ at room temperature a vigorous reaction is observed resulting in a thick black product. This study seeks to model the reaction of the titanium (IV) chloride with the mineral oil by using analogous compounds, in order to better understand this process.

Substituted esters were used to model the glyceride backbone of the oil as they both feature multiple ester groups linked by a short hydrocarbon backbone, this being the portion of the oil believed to interact with the metal chloride. Exposing these to excess $\mathrm{TiCl}_{4}$ allows the

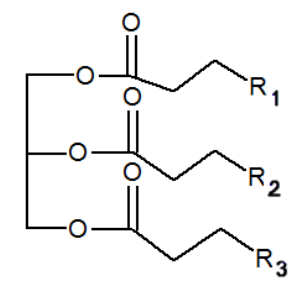

Figure 1: General structure of the triglyceride backbone of mineral oils. $R_{1}-R_{3}$ represent unsaturated alkyl chains $15-18$ carbon atoms in length.

interaction of the ester groups with the titanium centre to be studied. The esters used were diethyl malonate, diethyl succinate, dibenzyl malonate and glycerol tribenzoate. Titanium tetrachloride itself has a wide range of uses in the fields of inorganic chemistry, most notably as a key constituent of Zeigler-Natta catalysis. ${ }^{[11]}$ Additionally it is commonly used as a precursor for the production of thin films of $\mathrm{TiO}_{2} \cdot \cdot^{[12],[13]}$

Owing to this widespread use, a number of studies have been conducted concerning the formation and structure of complexes of $\mathrm{TiCl}_{4}$ and bidentate carbonyl ligands. Work by Maier et al. on the co-ordination of 3,3-dimethyl 2,4pentadione to $\mathrm{TiCl}_{4}$, suggests that two carbonyl oxygen atoms coordinate to the metal centre giving a six coordinate octahedral complex. ${ }^{[14]}$ Conversely a similar study found that unsubstituted 2,4-pentadione $(\mathrm{acacH})$ displaces one of the chloride ligands, leading to a dimeric $\left[\mathrm{TiCl}_{2}(\mathrm{acac}) \mu-\mathrm{Cl}\right]_{2}$ 
species. However a monomeric equivalent could be prepared by carrying out the reaction in tetrahydrofuran (THF) as opposed to $\mathrm{CH}_{2} \mathrm{Cl}_{2}$, with the THF acting as an Lewis base stabilising the monomeric species. ${ }^{[15]}$ Complexes of $\mathrm{TiCl}_{4}$ with diesters have been studied previously[16] using diethyl malonate. Like with acac, diethyl malonate acts as a bidentate ligand with the titanium coordinating to both carbonyl oxygen atoms. However, unlike acac, all of the chloride ligands were retained. The crystal structure showed that the ligand molecule was unchanged and the complexes adopted a distorted octahedral geometry.

This work studies the reaction of $\mathrm{TiCl}_{4}$ with multiple esters in order to better understand the insertion of the mineral oil in the chloride process, reporting four novel complexes of $\mathrm{TiCl}_{4}$ with the ester ligands, as well as a novel oxo bridged dimer of one of the products. The nature of the coordination observed could shed light on the chemical basis for why mineral oils are able to remove $\mathrm{VOCl}_{3}$ from a stream of gaseous $\mathrm{TiCl}_{4}$ without effect to the $\mathrm{TICl}_{4}$.

\section{Results and Discussion}

An excess of $\mathrm{TiCl}_{4}$ was treated with diester or triester ligands in hexane leading to the immediate precipitation of light yellow moisture sensitive solids which were washed repeatedly with hexane and then isolated in good yield (> $60 \%$ ). NMR spectra were obtained for each product, and single crystals grown using solvent layering in dichloromethane and hexane (2-4) or cooling in dichloromethane (1). In each case the ligand was observed to coordinate to the titanium centre, via both carbonyl oxygen atoms, forming a pseudo octahedral complex with the $\mathrm{TiCl}_{4}$. This was confirmed using single crystal $X$-ray diffraction data. All structures show the titanium centre adopting a sixcoordinate, distorted octahedral geometry.

Bond angles between the two oxygen atoms and the central titanium were lower than the expected octahedral angle of $90^{\circ}$ for all species. For instance tetrachloro (bis-isopropyl malonate) titanium(IV) [2a] has a O-Ti-O bond angle of $80.23(4)^{\circ}$. This can be explained by the chelating nature of the ligand and the greater atomic size of the chloride ligand compared with the oxygen. Chlorine has a van der Waals radius of $1.75 \AA$ whereas the van der Waals radius of oxygen is $1.52 \AA{ }^{[17]}$ leading to $\mathrm{Cl}-\mathrm{Ti}-\mathrm{Cl}$ angles of $98.51(3)^{\circ}$ in the same molecule, forcing the less electronegative carbonyl oxygen atoms closer together.

\subsection{Interaction of $\mathrm{TiCl}_{4}$ with Triglyceride Backbone Analogue Glycerol Tribenzoate [1]}

By using diesters and triesters as model compounds for the interaction of oils, their ability to remove other metal chlorides, while leaving $\mathrm{TiCl}_{4}$ can be better understood. By knowing the portion of the oil molecule responsible for the removal and how it happens, the most effective oil or combination of oils can be found, leading to improvements in the efficiency of the chloride process

Glycerol tribenzoate is a triester, meaning that of all the ligands in this study, it is the most representative of the glycerol group of the oil used for purification of $\mathrm{TiCl}_{4}$ in $\mathrm{TiO}_{2}$ production. Rather than unsaturated hydrocarbon chains however, in this case each ester group is linked to a benzene ring. This, simpler molecule serves as a close analogue to the structure and reactivity of the glyceride group of the oils used in the chloride process, however the absence of long alkyl chains makes the characterisation of the product, as well as the growth of single crystals more facile. Glycerol benzoate was reacted with excess $\mathrm{TiCl}_{4}$ under Schlenk conditions in hexane (Scheme 1). An excess of $\mathrm{TiCl}_{4}$ was used as the products' lack of solubility in hexane meant that the excess reagent could easily be removed via filtration. After two hours a yellow product was observed, which was washed with hexane and dried in vacuo. Crystals suitable for single $\mathrm{X}$-ray crystallography were grown by making a concentrated solution of $\mathbf{1}$ in dichloromethane and cooling to $-1^{\circ} \mathrm{C}$ for 1 month.

Figure 3. ORTEP representation of $\mathbf{1}$ as determined by single crystal $\mathrm{X}$ -

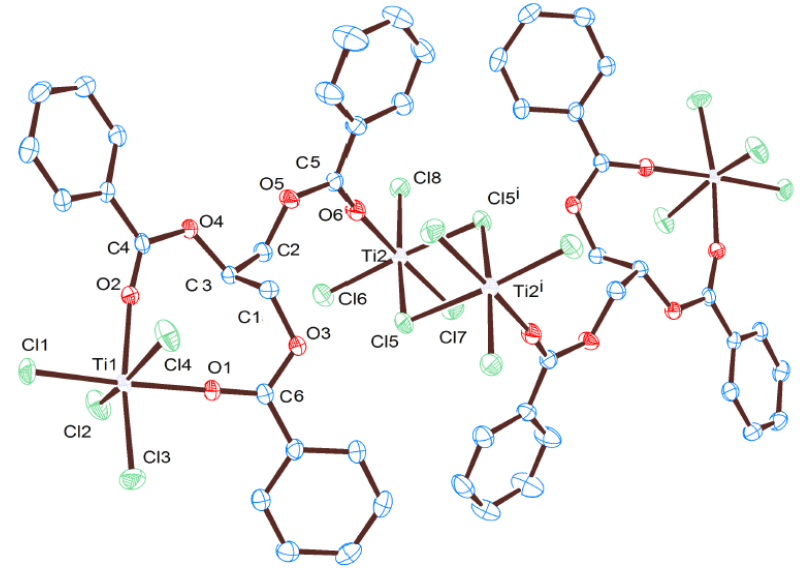

ray diffraction, with thermal ellipsoids at the $50 \%$ probability level. Hydrogen atoms and DCM omitted for clarity

The ${ }^{1} \mathrm{H}$ NMR spectrum for unreacted glycerol tribenzoate shows two sets of doublet of doublets at $\sim 4.7 \mathrm{ppm}$. These represent the inequivalent $\mathrm{CH}_{2}$ environments situated on the ends of the molecule's central propyl carbon chain, which couple to each other as well as the proton on the central carbon. Upon reaction of $\mathrm{TiCl}_{4}$ with the glycerol tribenzoate one of these peaks is shifted upfield by $0.2 \mathrm{ppm}$ whereas the other only shifts by $0.1 \mathrm{ppm}$.

The ${ }^{13} \mathrm{C}\left\{{ }^{1} \mathrm{H}\right\}$ NMR shows a shift for the signal of the carbonyl, upfield from 174 to $168 \mathrm{ppm}$ compared to the free ligand, which is due to the formation of a dative bond to the titanium centre reducing the shielding around the carbon. 


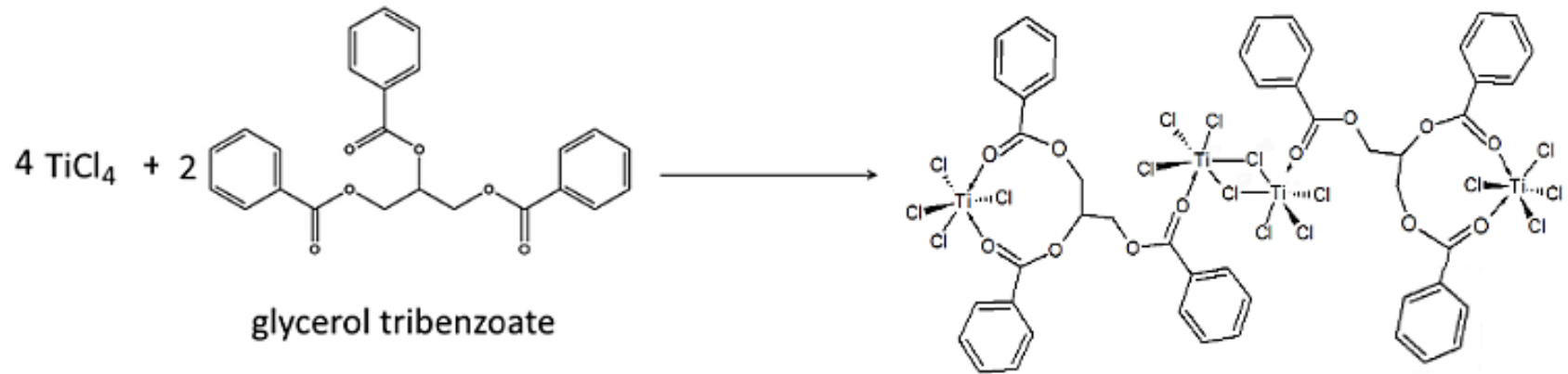

Scheme 1. Schematic of the synthesis of compound $\mathbf{1}$, formed by the reaction of $\mathrm{TiCl}_{4}$ in hexane with glycerol tribenzoate

The crystal structure of $\mathbf{1}$ shows two different environments for the $\mathrm{TiCl}_{4}$ bound to the glycerol tribenzoate. In one of these environments titanium is bound to four chlorine atoms and also to two carboxyl groups of the same glycerol tribenzoate. The bond distances and angles observed around this titanium centre, which adopts a distorted octahedral coordination geometry are similar to those observed for the diester complexes 2-4 (vide infra).

The third carbonyl oxygen atom of the glycerol benzoate molecule, rather than coordinating to the same titanium centre, which would be sterically unfavourable, coordinates to a second $\mathrm{TiCl}_{4}$ molecule. This leads to an electron deficient, 5 coordinate $\mathrm{TiCl}_{4}$ centre. This species would be highly unstable as a monomer and thus dimerises. A two chloro-bridged dimeric species is formed, with the two central titanium atoms taking on edge sharing octahedral geometry. The bridging $\mathrm{Ti}-\mathrm{Cl}$ bond distance of $2.5002(8) \AA$ is longer than the terminal $\mathrm{Ti}-\mathrm{Cl}$ bond distances observed to be on average 2.244(16) $\AA$, which is unsurprising as the electron density of the bridging chloride is shared between two metal centres rather than just one in the case of the terminal chlorine.

The formation of chloro-bridged bimetallic titanium species is relatively commonplace. Wu et al. reacted 2-propanol with $\mathrm{TiCl}_{4}$ to give a $\mathrm{Ti}_{2} \mathrm{Cl}_{8}$ dimer. ${ }^{[18]}$ What is of note in the case of this species is that despite the complexity of the molecule formed, there is no elimination of any chloride species as a result of the reaction, simply addition, followed by dimerisation of the resulting bimetallic species. This is of interest in relation to the chloride process as the $\mathrm{TiCl}_{4}$ is still intact within the molecule, and therefore at the high temperatures used in industrial synthesis, this coordination would be reversible.

\subsection{Interaction of $\mathrm{TiCl}_{4}$ with Diester Ligands}

In addition to the triester species, the interactions of the diesters; diisopropyl malonate, dibenzyl malonate and diethyl succinate with $\mathrm{TiCl}_{4}$ were also studied. Whilst less representative of the active species in the oils used for vanadium removal, these species were advantageous in that their simplicity allowed for single crystals to be obtained more easily, as well as yielding far less complex and easy to rationalize NMR spectra and still providing information regarding the potential reactivity of $\mathrm{TiCl}_{4}$ with ester functionality. As only two ester groups are present the species behave in the same way as the glycerol tribenzoate species without the third carbonyl species facilitating dimerisation. This may be of relevance as it is likely that the long alkyl chains of the oil could sterically hinder the dimerisation observed in 1, making it less favourable.

\section{i) Tetrachloro(diisopropyl malonate)-titanium(IV) [2a]}

Diisopropyl malonate was reacted with an excess of titanium (IV) chloride at room temperature, which yielded yellow crystals after layering in dichloromethane with hexane. NMR spectroscopy indicates a simple 1:1 coordination complex of the ligand and $\mathrm{TiCl}_{4}$. The ${ }^{1} \mathrm{H}$ NMR signal of the two protons of the central carbon atom between the two ester groups has shifted by $0.66 \mathrm{ppm}$ downfield in comparison to the free ligand. Likewise the signal of the isopropyl $\mathrm{CH}$ group had shifted by $0.42 \mathrm{ppm}$ and the signal of the four isopropyl $\mathrm{CH}_{3}$ groups have shifted by $0.25 \mathrm{ppm}$ when compared to the uncoordinated ligand.

Figure 4. ORTEP representation of the crystal structure of

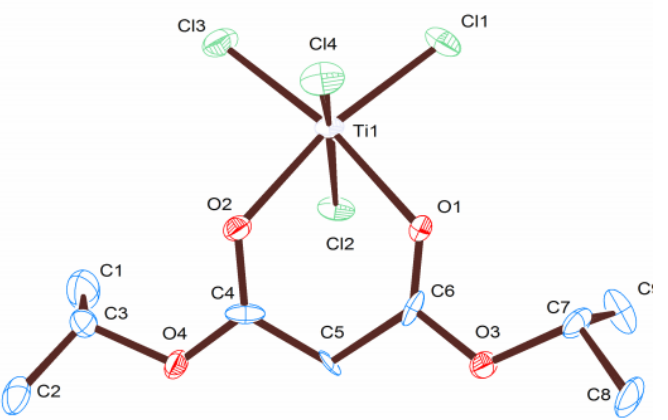

tetrachloro(diisopropyl malonate)-titanium(IV) [2a], with thermal ellipsoids at the $50 \%$ probability level. Hydrogen atoms omitted for clarity.

The structure of 2a was confirmed by single crystal XRD (Fig. 4). The malonate ligand forms a six membered ring structure with the titanium centre datively bound to the two carbonyls, linked in turn by a carbon chain. 


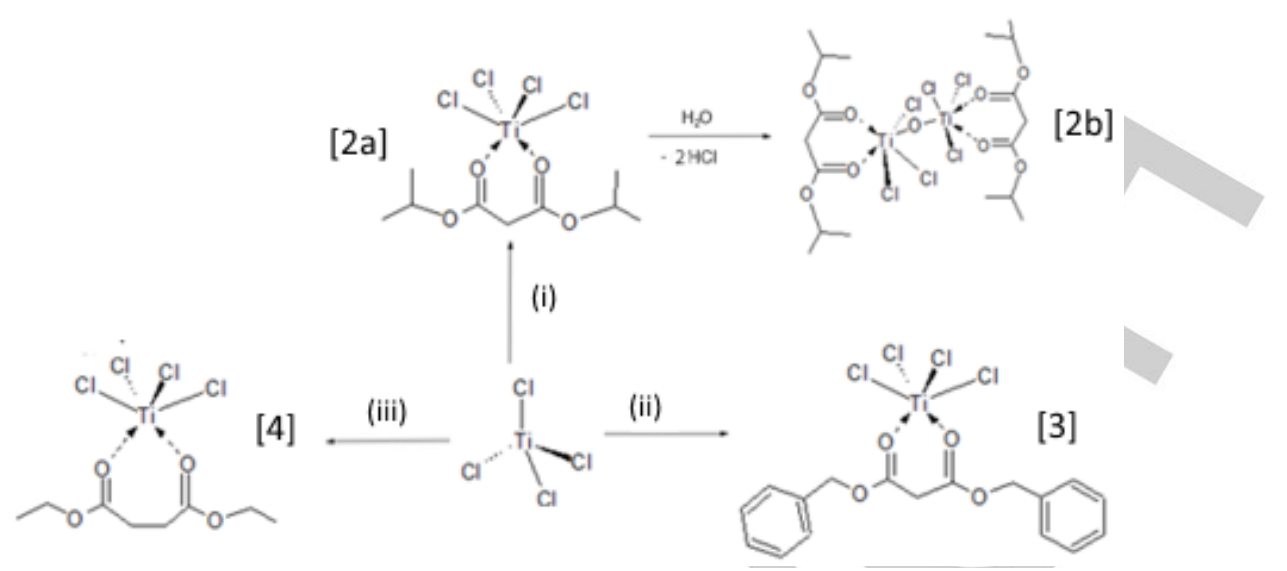

Scheme 2. Schematic of the synthesis of compounds 2-4, formed by the reaction of $\mathrm{TiCl}_{4}$ in hexane with: (i) diisopropyl malonate (2a, 2b), (ii) dibenzyl malonate (3), (iii) diethyl succinate (4)

The $\mathrm{C}(4)-\mathrm{O}(2)-\mathrm{Ti}(1)$ angle of the six membered ring species is considerably wider $\left(129.89(9)^{\circ}\right)$ than that expected for a flat hexagon $\left(120^{\circ}\right)$. Comparatively the O-Ti-O bond angle observed for this complex is $80.23(4)^{\circ}$, narrower than the expected $90^{\circ}$ due to the electronegativity of the chlorine atoms forcing the carbonyls closer together. This, combined with the differing length of Ti-O bonds $(\sim 2.1 \AA)$ and C-O bonds $(\sim 1.2 \AA)$ leads to considerable ring puckering. Sobota et al. observed similar angles when carrying out the related reaction with $\mathrm{TiCl}_{4}$ and diethyl malonate. ${ }^{16}$

The length of the bond between the titanium and the carbonyl oxygen on the diisopropyl malonate is $2.123(3) \AA$. This is far closer to the dative $\mathrm{Ti}-\mathrm{O}$ bond length of $\left[\mathrm{TiCl}_{4}(\mathrm{THF})_{2}\right]^{[19,20]}$ than that of a covalent $\mathrm{Ti}-\mathrm{O}$ bond $^{27}$ and is due to the coordination of the bis-isopropyl malonate being dative, via a lone pair on each the carbonyl oxygen atoms.

ii) Bis-trichloro- $\mu$-oxo-(diisopropyl malonate)titanium(IV) [2b]

This dimeric species was produced during the same synthesis as $2 a$ described above. The formation of the dimer is the result of moisture being present in the system, most likely due to the reaction vessel being insufficiently dry. The reaction produced yellow crystals, after workup. Two noticeably different types of crystal were observed, both of which were characterized by single crystal X-ray diffraction. While all of the other compounds observed in this paper form as a result of simple addition of the ligand to the tetrahedral $\mathrm{TiCl}_{4}$ with no displacement of chlorine, $\mathbf{2} \mathbf{b}$ contains titanium centres linked by an oxygen atom, facilitated by loss of chlorine. This was likely a result of a small amount of air entering the vessel, which lead to reaction of water with the product in which the addition of oxygen is facilitated by the formation of $\mathrm{HCl}$ gas. This affect has been reported with similar titanium chloride complexes, leading to oxo bridged dimers and tetramers. ${ }^{[21]}$ The bond distances between the bridging oxygen and the titanium centres was 1.741(7) and $1.863(7) \AA$, showing the bonding to be covalent in nature ${ }^{28}$.
The bridging oxygen stabilised the system and similar bridging compounds have been reported before as easier to crystallise when large stabilising ligands are removed. [22] The bond angles and distances in the two bridged titanium centres of $\mathbf{2} \mathbf{b}$ are similar to those reported. The bridging Ti$\mathrm{O}-\mathrm{Ti}$ bond angle is $177.3(5)^{\circ}$ which is similar to other oxobridged titanium chloride dimers with alkoxide ligands that are less sterically hindering. ${ }^{[22],[23]}$ In the presence of bulkier ligands, more acute oxo bridge angles have been reported. [21] The formation of the dimer demonstrates how air/moisture sensitive this system is and how any form of oxygen can stabilise the product.

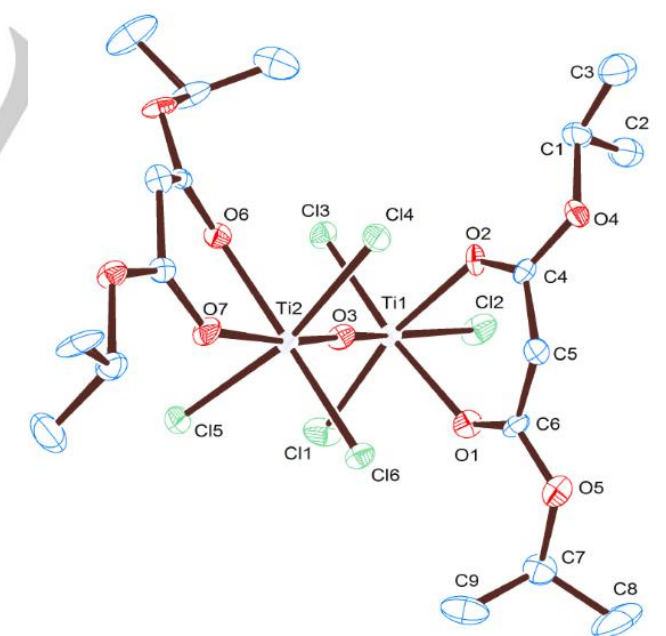

Figure 5. ORTEP representation of $\mathbf{2 b}$ with thermal ellipsoids at the $50 \%$ probability level. Hydrogen atoms omitted for clarity.

\section{iii) Tetrachloro(dibenzylmalonate)-titanium(IV) [3]}

Dibenzyl malonate was reacted with an excess of titanium (IV) chloride at room temperature, which yielded yellow crystals after layering in dichloromethane with hexane. 


\begin{tabular}{|c|c|c|c|c|c|}
\hline \multicolumn{6}{|c|}{ Table 1: Crystallographic data for compounds 1-4 } \\
\hline Ligand & $\begin{array}{l}\text { [1] Glycerol } \\
\text { Tribenzoate }\end{array}$ & $\begin{array}{l}\text { [2a] diisopropyl } \\
\text { malonate }\end{array}$ & $\begin{array}{l}\text { [2b] diisopropyl } \\
\text { malonate dimer }\end{array}$ & $\begin{array}{c}\text { [3] dibenzyl } \\
\text { malonate }\end{array}$ & $\begin{array}{l}\text { [4] diethyl } \\
\text { succinate }\end{array}$ \\
\hline crystal system & Triclinic & Monoclinic & triclinic & monoclinic & monoclinic \\
\hline space group & P-1 & $\mathrm{P} 21 / \mathrm{c}$ & $\mathrm{P} 21 / \mathrm{C}$ & P21 & C 2/c \\
\hline$a$ & 9.9955(3) A & $6.6655(14) \AA$ & 18.335(16) $\AA$ & $16.3215(4) \AA$ & $16.6592(11) \AA$ \\
\hline$b$ & $13.9772(3) \AA$ & $12.954(3) \AA$ & $12.436(12) \AA$ & $9.5645(2) \AA$ & 8.5418(5) $\AA$ \\
\hline$c$ & $14.4644(4) \AA$ & 18.983(5) A & $13.683(11) \AA$ & $19.7379(4) \AA$ & $10.3708(7) \AA$ \\
\hline$\alpha$ & $71.868(2)^{\circ}$ & $90.000^{\circ}$ & $90.000^{\circ}$ & $90.000^{\circ}$ & $90.000(5)^{\circ}$ \\
\hline$\beta$ & $76.307(2)^{\circ}$ & $90.032(4)^{\circ}$ & $102.474(14)^{\circ}$ & $90.069(2)^{\circ}$ & $98.836(3)^{\circ}$ \\
\hline Y & $77.073(2)^{\circ}$ & $90.000^{\circ}$ & $90.000^{\circ}$ & $90.000^{\circ}$ & $90.000(5)^{\circ}$ \\
\hline $\mathrm{R}_{1}$ & 0.0381 & 0.0230 & 0.1153 & 0.0822 & 0.0244 \\
\hline$w_{2}$ & 0.0977 & 0.0569 & 0.3054 & 0.2161 & 0.0669 \\
\hline
\end{tabular}

Table 2: Selected bond angles for compounds 1-4

$\begin{array}{cccccc}\text { Bond Angle } & \begin{array}{c}\text { [1] Glycerol } \\ \text { Tribenzoate }\end{array} & \begin{array}{c}\text { [2a] diisopropyl } \\ \text { malonate }\end{array} & \begin{array}{c}\text { [2b] diisopropyl } \\ \text { malonate dimer }\end{array} & \begin{array}{c}\text { [3] dibenzyl } \\ \text { malonate }\end{array} & \begin{array}{c}\text { [4] diethyl } \\ \text { succinate }\end{array} \\ \mathrm{C}(4)-\mathrm{O}(2)-\mathrm{Ti}(1) & 164.3(2) & 129.89(9) & 133.0(7) & 134.6(5) & 136.55(10) \\ \mathrm{C}(6)-\mathrm{O}(1)-\mathrm{Ti}(1) & 170.7(2) & 131.45(9) & 131.2(8) & 134.4(4) & 136.55(10) \\ \mathrm{O}(1)-\mathrm{Ti}(1)-\mathrm{O}(2) & 83.59(8) & 80.23(4) & 80.0(3) & 79.33(19) & 86.26(6) \\ \mathrm{O}(1)-\mathrm{Ti}(1)-\mathrm{Cl}(3) & 177.38(7) & 170.85(3) & 167.3(3) & 169.39(16) & 173.87(3) \\ \mathrm{O}(1)-\mathrm{Ti}(1)-\mathrm{Cl}(4) & 87.98(6) & 84.68(3) & \mathrm{n} / \mathrm{a} & 82.63(16) & 83.57(3) \\ \mathrm{Cl}(1)-\mathrm{Ti}(1)-\mathrm{Cl}(4) & 94.63(3) & 97.21(2) & \mathrm{n} / \mathrm{a} & 95.47(8) & 95.985(15) \\ \mathrm{O}(1)-\mathrm{Ti}(1)-\mathrm{Cl}(1) & 93.79(6) & 90.40(3) & 92.3(2) & 90.59(15) & 88.39(3) \\ \mathrm{Cl}(1)-\mathrm{Ti}(1)-\mathrm{Cl}(3) & 98.32(4) & 98.44(2) & 100.31(14) & 99.96(9) & 97.10(2) \\ \mathrm{O}(1)-\mathrm{Ti}(1)-\mathrm{Cl}(2) & 84.49(7) & 83.26(3) & 81.7(2) & 84.78(16) & 86.39(3) \\ \mathrm{Cl}(3)-\mathrm{Ti}(1)-\mathrm{Cl}(2) & 95.38(3) & 93.86(2) & 96.22(16) & 95.28(8) & 95.985(15) \\ \mathrm{O}(6)-\mathrm{Ti}(2)-\mathrm{Cl}(7) & 171.73(7) & \mathrm{n} / \mathrm{a} & \mathrm{n} / \mathrm{a} & \mathrm{n} / \mathrm{a} & \mathrm{n} / \mathrm{a} \\ \mathrm{O}(6)-\mathrm{Ti}(2)-\mathrm{Cl}(6) & 90.13(7) & \mathrm{n} / \mathrm{a} & 168.9(2) & \mathrm{n} / \mathrm{a} & \mathrm{n} / \mathrm{a} \\ \mathrm{O}(6)-\mathrm{Ti}(2)-\mathrm{Cl}(5 \mathrm{i}) & 84.62(7) & \mathrm{n} / \mathrm{a} & \mathrm{n} / \mathrm{a} & \mathrm{n} / \mathrm{a} & \mathrm{n} / \mathrm{a} \\ \mathrm{Cl}(5)-\mathrm{Ti}(2)-\mathrm{Cl}(8) & 167.70(4) & \mathrm{n} / \mathrm{a} & \mathrm{n} / \mathrm{a} & \mathrm{n} / \mathrm{a} & \mathrm{n} / \mathrm{a} \\ \mathrm{Cl}(5 \mathrm{i})-\mathrm{Ti}(2)-\mathrm{Cl}(8) & 92.11(3) & \mathrm{n} / \mathrm{a} & \mathrm{n} / \mathrm{a} & \mathrm{n} / \mathrm{a} & \\ \mathrm{Cl}(5 \mathrm{i})-\mathrm{Ti}(2)-\mathrm{Cl}(5) & 78.41(3) & \mathrm{n} / \mathrm{a} & & & \mathrm{n} / \mathrm{a} \\ & & & & & \end{array}$

$\begin{array}{cccccc}\text { [1] Glycerol } & \begin{array}{c}\text { Table 3: Selected bond lengths for compounds 1-4 } \\ \text { [2a] diisopropyl } \\ \text { malonate }\end{array} & \begin{array}{c}\text { [2b] diisopropyl } \\ \text { malonate dimer }\end{array} & \begin{array}{c}\text { [3] dibenzyl } \\ \text { malonate }\end{array} & \begin{array}{c}\text { [4] diethyl } \\ \text { succinate }\end{array} \\ \mathrm{Cl}(3)-\mathrm{Ti}(1) & 2.2258(9) & 2.2312(6) & 2.230(4) & 2.224(4) & 2.2379(4) \\ \mathrm{Cl}(4)-\mathrm{Ti}(1) & 2.2756(9) & 2.2519(5) & \mathrm{n} / \mathrm{a} & 2.303(2) & 2.3070(4) \\ \mathrm{O}(2)-\mathrm{Ti}(1) & 2.124(2) & 2.1032(10) & 2.136(8) & 2.115(5) & 2.123(2) \\ \mathrm{O}(1)-\mathrm{Ti}(1) & 2.101(2) & 2.1120(10) & 2.129(8) & 2.122(5) & 2.1101(10) \\ \mathrm{C}(4)-\mathrm{O}(2) & 1.228(3) & 1.2340(15) & 1.225(14) & 1.221(8) & 1.2408(18) \\ \mathrm{Cl}(1)-\mathrm{Ti}(1) & 2.2234(8) & 2.2322(5) & 2.222(4) & 2.213(2) & 2.2379(4) \\ \mathrm{Cl}(2)-\mathrm{Ti}(1) & 2.2938(9) & 2.3414(5) & 2.306(4) & 2.292(2) & 2.3070(4) \\ \mathrm{C}(6)-\mathrm{O}(1) & 1.227(3) & 1.2294(16) & 1.233(14) & 1.224(8) & 1.2408(18) \\ \mathrm{Ti}(2)-\mathrm{Cl}(5) & 2.5002(8) & \mathrm{n} / \mathrm{a} & 2.373(3) & \mathrm{n} / \mathrm{a} & \mathrm{n} / \mathrm{a} \\ \mathrm{Ti}(2)-\mathrm{Cl}(7) & 2.2328(9) & \mathrm{n} / \mathrm{a} & \mathrm{n} / \mathrm{a} & \mathrm{n} / \mathrm{a} & \mathrm{n} / \mathrm{a} \\ \mathrm{Ti}(2)-\mathrm{O}(6) & 2.020(2) & \mathrm{n} / \mathrm{a} & \mathrm{n} / \mathrm{a} & \mathrm{n} / \mathrm{a} & \mathrm{n} / \mathrm{a} \\ \mathrm{O}(3)-\mathrm{Ti}(2) & \mathrm{n} / \mathrm{a} & \mathrm{n} / \mathrm{a} & 1.741(7) & \mathrm{n} / \mathrm{a} & \mathrm{n} / \mathrm{a} \\ \mathrm{O}(3)-\mathrm{Ti}(1) & \mathrm{n} / \mathrm{a} & \mathrm{n} / \mathrm{a} & 1.863(7) & \mathrm{n} / \mathrm{a} & \mathrm{n} / \mathrm{a}\end{array}$


NMR spectroscopy revealed that the ligand coordinated to the metal centre, in a manner similar to compound $2 \mathbf{a}$ The ${ }^{1} \mathrm{H}$ NMR spectra of $\mathbf{3}$ shows the signal of the two central protons to shift $0.50 \mathrm{ppm}$ downfield from the free ligand. Signals from the two $\mathrm{CH}_{2}$ groups adjacent to the ester oxygen shifted by $0.32 \mathrm{ppm}$. Finally the benzyl proton signals, a single broad peak in the spectrum of the uncoordinated ligand is shifted to reveal two of the overlapping phenyl group proton signals. The ortho protons shifting downfield by $0.9 \mathrm{ppm}$, the meta and para by only $0.5 \mathrm{ppm}$. As described for the diisopropyl malonate, the complex features a puckered six membered ring (Fig. 6).

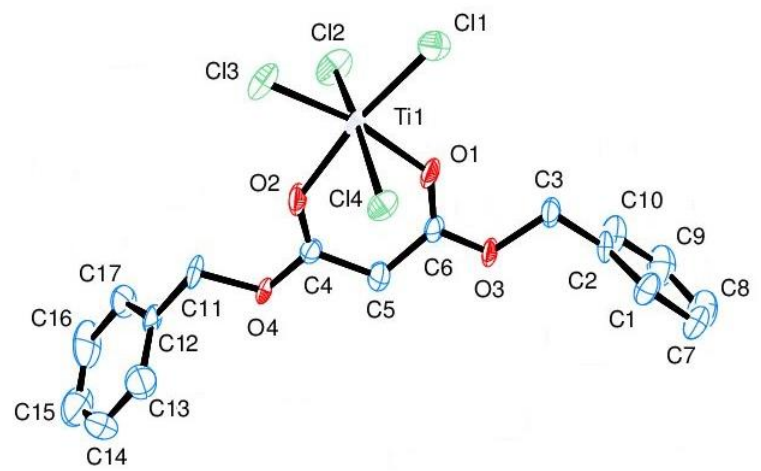

Figure 6. ORTEP representation of tetrachloro (dibenzyl malonate)titanium(IV) [3] with thermal ellipsoids at the 50\% probability level. Hydrogen atoms omitted for clarity.

Like compound $\mathbf{2 a}$, the repulsion of the four chlorine ligands resulted in the subsequent compression of the O-Ti-O bond angle to $79.33(19)^{\circ}$. As with the diisopropyl malonate complex, the Ti-O bond length of 2.122(5) $\AA$ suggests that the bond between the titanium and the carbonyl is dative in nature.

\section{iv) Tetrachloro(diethyl succinate)-titanium(IV) [4]}

Diethyl succinate was reacted with an excess of titanium (IV) chloride in hexane at room temperature, which yielded yellow crystals after dichloromethane/hexane layering. NMR once again revealed that the ligand had coordinated to the metal centre unchanged, forming a simple 1:1 adduct. This was confirmed by single crystal X-ray diffraction. Like other complexes synthesised in this work, this structure contains a ring system formed by the bidentate coordination of the ligand to the metal centre. In this case however the ring is seven membered. As with the compounds $\mathbf{2 a}$ and $\mathbf{3}$ the ring is puckered, taking on the boat chair conformer, and distorted by the presence of the chloride ligands to give an acute $\mathrm{Ti}$ O-Ti bond angle of $86.26(6)^{\circ}$ (Fig. 7).

This is to our knowledge the first time that a succinate ligand has been coordinated to titanium chloride. Due to the increased rigidity and shorter $\mathrm{C}-\mathrm{C}$ bond length resulting from the double bond, the malonate structure is more strained, with a Ti-O-Ti bond angle of $81.2^{\circ}$. As with the structure reported here for compound $\mathbf{2 a}$, due to the dative nature of the coordination between the malonate ligand and the $\mathrm{Ti}$ centre the metal oxygen distance is longer $(2.1101(10) \AA$ ) than for other compounds of this type.

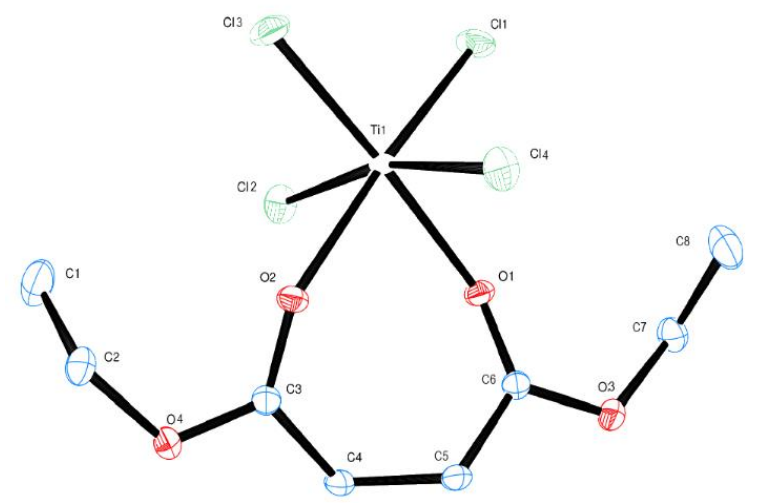

Figure 7. ORTEP representation of the crystal structure of tetrachloro (diethyl succinate)-titanium(IV) [4] with thermal ellipsoids at the $50 \%$ probability level. Hydrogen atoms omitted for clarity

\section{Conclusion}

All three of the diesters studied coordinated to the titanium (IV) chloride in the same way, forming complexes with a distorted octahedral geometry. Exposure of the reaction of diisopropyl malonate and titanium (IV) chloride to air lead to the formation of a dimeric, oxo-bridged species, following the loss of a chloride from the metal centre. Each diester undergoes bidentate coordination to the titanium centre, forming a distorted octahedral structure with no loss of chlorine.

Glycerol tribenzoate coordinated in a similar way to the other species, with two of the ester groups datively coordinating via the carbonyl oxygen to a single titanium centre leading to a similar octahedral geometry. The third ester carbonyl group coordinates to a second titanium chloride molecule. The resulting species instability leads to dimerization. Formation of a two choro-bridged $\mathrm{Ti}_{2}\left(\mu^{2}-\mathrm{Cl}_{2}\right) \mathrm{Cl}_{6}$ centre was observed, with both titanium centres coordinated to a single carbonyl oxygen of a different glycerol benzoate molecule. As with the other structures, no chlorine loss is observed.

The addition of oil in the chloride process for the production of $\mathrm{TiO}_{2}$ is carried out at around $200^{\circ} \mathrm{C}$, at which point all of the metal chlorides present are in the vapour phase. At this temperature, the dative coordination would likely be more reversible, as neither the $\mathrm{TiCl}_{4}$ nor the esters are altered structurally by coordination. This is not the case for vanadium oxytrichloride species. This could explain why, in the chloride process the $\mathrm{TiCl}_{4}$ is able to pass through without reacting with the oil. 
Conversely the addition of donor ligands to $\mathrm{VOCl}_{3}$, the species removed by the oil, frequently causes the dissociation of one of the chlorine atoms, sometimes via the entropically favourable dissociation of $\mathrm{HCl}$, leaving a $\mathrm{VOCl}_{2} \mathrm{~L}$ species. ${ }^{[24]}$ This has been shown to occur for a number of keto-ligands that would coordinate to $\mathrm{TICl}_{4}$ without loss of chlorine. This suggest that although the Lewis acidy of the $\mathrm{TiCl}_{4}$ is greater than $\mathrm{VOCl}_{3}$, the $\mathrm{VOCl}_{3}$ may be changed irreversibly by reaction with carbonyl groups in the oils, making it the preferred species as the energy barrier to reversibility would be greater.

\section{Experimental}

All reactions were carried out under argon obtained from BOC using standard Schlenk techniques. All Solvents were dried over activated alumina by the Grubbs method using anhydrous engineering equipment, such that the water concentration was $5-10$ ppm. ${ }^{[25]}$ Anhydrous $\mathrm{TiCl}_{4}$ and malonate starting materials were purchased from Sigma Aldrich; all were used without further purification. ${ }^{1} \mathrm{H}$ and ${ }^{13} \mathrm{C}\left\{{ }^{1} \mathrm{H}\right\}$ NMR spectra were obtained on a Bruker AV- $600 \mathrm{Mz}$ spectrometer, operating at $295 \mathrm{~K}$ and $600.13 \mathrm{MHz}\left({ }^{1} \mathrm{H}\right)$. Signals are reported relative to $\mathrm{SiMe}_{4}(\delta=0.00 \mathrm{ppm})$ and the following abbreviations are used s (singlet), $d$ (doublet), t (triplet), q (quartet), $\mathrm{m}$ (multiplet), b (broad). $\mathrm{CDCl}_{3}$ was obtained from GOSS Scientific and was dried and degassed over $3 \AA \AA$ molecular sieves.

Synthesis of complex of titanium(IV) chloride with glycerol tribenzoate [1]. Glycerol tribenzoate $(0.5 \mathrm{~g}, 1.2 \mathrm{mmol})$ was added gradually to $\mathrm{TiCl}_{4}\left(2.0 \mathrm{~cm}^{3}, 18.2 \mathrm{mmol}\right)$ in $50 \mathrm{~cm}^{3}$ of hexane and stirred under argon for $2 \mathrm{~h}$. An excess of $\mathrm{TiCl}_{4}$ was used as its removal after reaction completion is facile. Gradual precipitation of a yellow product was observed. The solvent and excess $\mathrm{TiCl}_{4}$ was removed via filtration and the precipitate was filtered and washed three times with $20 \mathrm{~cm}^{3}$ hexane before drying in vacuo to afford $\mathbf{1}$ in good yield (1.6 g 75\%). Crystals suitable for X-ray diffraction were obtained by dissolving the yellow product in a minimum amount of dichloromethane, cooling to $-10{ }^{\circ} \mathrm{C}$, and leaving for one month. ${ }^{1} \mathrm{H}$ $\mathrm{NMR}\left(\mathrm{CDCl}_{3}\right): \delta 8.27$ (d, $\left.2 \mathrm{H}, o-\mathrm{CH}, \mathrm{J}=7.7 \mathrm{~Hz}\right), 8.17(\mathrm{~d}, 4 \mathrm{H}, o-\mathrm{CH}, \mathrm{J}$ $=7.7 \mathrm{~Hz}), 7.69\left(\mathrm{t}, 2 \mathrm{H},-\mathrm{CH}_{2}, \mathrm{~J}=4.8 \mathrm{~Hz}, 12.3 \mathrm{~Hz}\right), 7.65(\mathrm{t}, 1 \mathrm{H}, p-\mathrm{CH}$, $\mathrm{J}=7.7 \mathrm{~Hz}), 7.53(\mathrm{t}, 1 \mathrm{H}, \mathrm{m}-\mathrm{CH}, \mathrm{J}=7.7 \mathrm{~Hz}), 7.50(\mathrm{t}, 1 \mathrm{H}, \mathrm{m}-\mathrm{CH}, \mathrm{J}=7.7$ $\mathrm{Hz}$ ), 5.82 (quin, $1 \mathrm{H},-\mathrm{OCH}, \mathrm{J}=5.1 \mathrm{~Hz}$ ), 4.98 (dd, $2 \mathrm{H},-\mathrm{CH}_{2}, \mathrm{~J}=4.8$ $\mathrm{Hz}, 12.3 \mathrm{~Hz}$ ), 4.75 (dd, $\left.2 \mathrm{H},-\mathrm{CH}_{2}, \mathrm{~J}=4.8 \mathrm{~Hz}, 12.3 \mathrm{~Hz}\right) .{ }^{13} \mathrm{C}\left\{{ }^{1} \mathrm{H}\right\} \mathrm{NMR}$ (CDCl3): $\delta 63.5\left(\mathrm{CH}_{2}\right), 72.23(\mathrm{CH}), 129(o-\mathrm{CH}), 131(p-\mathrm{CH}), 135(m-$ $\mathrm{CH}), 168(\mathrm{C}=\mathrm{O})$. Elemental analysis calculated for $\mathrm{Ti}_{4} \mathrm{Cl}_{6} \mathrm{C}_{48} \mathrm{O}_{12} \mathrm{H}_{46}$ : C, 36.64; H, 2.95. Found: C, 37.6; H, 2.98 .

Synthesis of tetrachloro(diisopropyl malonate)-titanium(IV) [2a]. Diisopropyl malonate $\left(0.5 \mathrm{~cm}^{3}, 3.3 \mathrm{mmol}\right)$ was added drop wise to $\mathrm{TiCl}_{4}\left(1.0 \mathrm{~cm}^{3}, 9.1 \mathrm{mmol}\right)$ in $50 \mathrm{~cm}^{3}$ of hexane and stirred under argon for $2 \mathrm{~h}$. A yellow precipitate was immediately formed and the reaction was stirred for a further $2 \mathrm{~h}$ to ensure completion. The solvent and excess $\mathrm{TiCl}_{4}$ removed via filtration and the precipitate was filtered and washed three times with $20 \mathrm{~cm}^{3}$ hexane before drying in vacuo to afford complex $2 \mathrm{a}$ in good yield $(0.8 \mathrm{~g}, 63 \%)$. Some of the product was re-dissolved in $5 \mathrm{~cm}^{3}$ of dichloromethane and layered with 15 $\mathrm{cm}^{3}$ of hexane. After $48 \mathrm{~h}$ small crystals formed. The molecular structure of $2 \mathrm{a}$ was determined by $\mathrm{X}$-ray crystallography. ${ }^{1} \mathrm{H}$ NMR $\left(\mathrm{CDCl}_{3}\right)$ : $\delta 5.46$ (b, 2H, $\left.-\mathrm{CH}\right), 3.95\left(\mathrm{~b}, 2 \mathrm{H},-\mathrm{CH}_{2}\right), 1.47\left(\mathrm{~d}, 12 \mathrm{H},-\mathrm{CH}_{3}\right.$, $\mathrm{J}=6.2 \mathrm{OHz}) \cdot{ }^{13} \mathrm{C}\left\{{ }^{1} \mathrm{H}\right\} \operatorname{NMR}\left(\mathrm{CDCl}_{3}\right): \delta 21.7\left(-\mathrm{CH}_{3}\right), 38.0\left(-\mathrm{CH}_{2}\right), 54.8$ $\left(-\mathrm{OCH}_{2}\right), 172(\mathrm{C}=\mathrm{O})$. Elemental analysis calculated for $\mathrm{TiCl}_{4} \mathrm{C}_{9} \mathrm{O}_{4} \mathrm{H}_{16}$ : C, 28.60; H, 4.27. Found: C, 26.03; H, 3.45.

When 2a was crystallised, two types of crystals were observed, block type and plate type. Carrying out single crystal XRD on both types revealed that a second product had formed $(\mathbf{2 b})$, a dimeric species consisting of two titanium centres linked by a bridging oxygen, each coordinate to one malonate ligand. The additional oxygen that entered the system is likely responsible for the discrepancy between calculated atomic percentage and that found through elemental analysis.

Synthesis of tetrachloro(dibenzyl malonate)-titanium(IV) [3] Dibenzyl malonate $\left(1.0 \mathrm{~cm}^{3}, 3.5 \mathrm{mmol}\right)$ was added drop wise to $\mathrm{TiCl}_{4}\left(1.0 \mathrm{~cm}^{3}, 9.1\right.$ $\mathrm{mmol}$ ) in $50 \mathrm{~cm}^{3}$ of hexane. A yellow precipitate was observed immediately and the reaction was stirred under argon for $2 \mathrm{~h}$. The solvent and excess $\mathrm{TiCl}_{4}$ removed via filtration and the precipitate was filtered and washed three times with $20 \mathrm{~cm}^{3}$ hexane before drying in vacuo to afford 3 . A good yield was recovered $(1.2 \mathrm{~g}, 77 \%)$. Yellow crystals were again formed from a solution in $\mathrm{CH}_{2} \mathrm{Cl}_{2}$ layered with hexane. The molecular structure of 3 was determined by X-ray crystallography. ${ }^{1} \mathrm{H}$ NMR $\left(\mathrm{CDCl}_{3}\right): \delta 7.4(\mathrm{~m}, 10 \mathrm{H}, \mathrm{Ph})$, $5.5\left(\mathrm{~b}, 4 \mathrm{H},-\mathrm{CH}_{2}\right), 4.0\left(\mathrm{~b}, 2 \mathrm{H},-\mathrm{CH}_{2}\right) \cdot{ }^{13} \mathrm{C}\left\{{ }^{1} \mathrm{H}\right\} \mathrm{NMR}\left(\mathrm{CDCl}_{3}\right): \delta 38.0\left(-\mathrm{CH}_{2}\right)$, $73.0\left(-\mathrm{OCH}_{2}\right), 129-130(\mathrm{~m}, \mathrm{C} 6,-\mathrm{Ph})$. Elemental analysis calculated for $\mathrm{TiCl}_{4} \mathrm{C}_{15} \mathrm{O}_{4} \mathrm{H}_{12}: \mathrm{C}, 43.08 ; \mathrm{H}, 3.40$. Found: $\mathrm{C}, 43.24 ; \mathrm{H}, 3.40$.

Synthesis of tetrachloro(diethyl succinate)-titanium(IV) [4] Diethyl succinate $\left(0.5 \mathrm{~cm}^{3}, 3.3 \mathrm{mmol}\right)$ was added drop wise to $\mathrm{TiCl}_{4}$ $\left(2.0 \mathrm{~cm}^{3}, 18.2 \mathrm{mmol}\right)$ in $50 \mathrm{~cm}^{3}$ of hexane and stirred under argon for $2 \mathrm{~h}$. A yellow precipitate formed immediately, the reaction was stirred for $2 \mathrm{~h}$ to ensure completion. The yellow precipitate was filtered off and washed three times with $10 \mathrm{~cm}^{3}$ hexane and dried in vacuo, to afford complex 3 in good yield $(0.9 \mathrm{~g}, 75 \%)$. The product was redissolved in $5 \mathrm{~cm}^{3}$ dichloromethane and layered with $10 \mathrm{~cm}^{3}$ hexane. Small crystals formed overnight allowing the molecular structure of 3 to be determined by X-ray crystallography. ${ }^{1} \mathrm{H} \mathrm{NMR}\left(\mathrm{CDCl}_{3}\right)$ : $\delta 4.61$ (q, $4 \mathrm{H},-\mathrm{CH}_{2}, \mathrm{~J}=14.3 \mathrm{~Hz}$ ), $3.08\left(\mathrm{~s}, 4 \mathrm{H},-\mathrm{CH}_{2}\right), 1.46\left(\mathrm{t}, 6 \mathrm{H},-\mathrm{CH}_{3}, \mathrm{~J}=\right.$ $14 \mathrm{~Hz}),{ }^{13} \mathrm{C}\left\{{ }^{1} \mathrm{H}\right\}$ NMR $\left(\mathrm{CDCl}_{3}\right): \delta 14.1\left(-\mathrm{CH}_{3}\right), 29.2\left(-\mathrm{CH}_{2} \mathrm{CH}_{2}\right), 66.2$ $\left(-\mathrm{OCH}_{2}\right), 179(\mathrm{C}=\mathrm{O})$. Elemental analysis calculated for $\mathrm{TiCl}_{4} \mathrm{C}_{8} \mathrm{O}_{4} \mathrm{H}_{14}$ : C, 26.4; H, 3.88. Found: C, 26.41; H, 3.40.

\section{Crystallography}

Suitable crystals were selected and mounted on a nylon loop, datasets of $\mathbf{2} \mathbf{a}$ and $\mathbf{2} \mathbf{b}$ were collected on a Rigaku AFC12 goniometer equipped with an enhanced sensitivity (HG) Saturn724+ detector mounted at the window of an FR-E+ SuperBright molybdenum rotating anode generator $\left(\lambda_{1}=0.71073 \AA\right.$ ) with VHF Varimax optics (100 $\mu \mathrm{m}$ focus). Crystals of compound $\mathbf{2 b}$ were of poor quality and did not diffract well, leading to a low-quality dataset. Although the atomic connectivity is unambiguous, the high $R$ factors $\left(R_{1}=0.1153\right.$, $\left.\mathrm{wR}_{2}=0.3054\right)$ and low precision on $\mathrm{C}-\mathrm{C}$ bond lengths preclude accurate comparison of bond lengths and angles. The diffraction 
pattern for $\mathbf{4}$ was obtained using a Rigaku R-Axis Spider diffractmeter including curved Fujifilm image plate and a graphite monochromated sealed tube Mo generator $\left(\lambda_{1}=0.71073 \AA\right)$. The datasets of 1 and 3 were collected on a SuperNova, Dual, $\mathrm{Cu}$, Atlas diffractometer. The crystal was kept at $150 \mathrm{~K}$ during data collection. $\mathbf{2 a}$, 2b, and $\mathbf{4}$ were solved using Cell determination, data collection, data reduction, cell refinement and absorption correction were carried out using CrystalClear-SM Expert 3.1 b18. ${ }^{[26]}$ Structure solution and refinement were carried out using WinGX and software packages. ${ }^{[27]} \mathrm{H}$ atoms attached to $\mathrm{C}$ atoms were placed in geometrically assigned positions, with $\mathrm{C}$-H distances of $0.95 \AA(\mathrm{CH}), 0.98 \AA\left(\mathrm{CH}_{3}\right)$ or $0.99 \AA\left(\mathrm{CH}_{2}\right)$ and refined using a riding model, with $U_{\text {iso }}(\mathrm{H})=1.2 U_{\text {eq }}(\mathrm{C})\left(\mathrm{CH}, \mathrm{CH}_{2}\right)$ or $1.5 U_{e q}(\mathrm{C}) \quad\left(\mathrm{CH}_{3}\right)$. enClFer was used to sprepare CIFs for publication. ${ }^{[28]}$ Compounds 1 and $\mathbf{3}$ were solved using Olex2, ${ }^{[29]}$ the structure was solved with the olex2.solve ${ }^{[30]}$ structure solution program using Charge Flipping and refined with the ShelXL ${ }^{[31]}$ refinement package using Least Squares minimisation. All structures have been submitted to the CCDC; compound 1 CCDC 1017261 , compound 2a CCDC 1045710, compound 2b CCDC 1045712 compound 3 CCDC 1044806, compound 4 CCDC 1045711.

\section{Acknowledgements}

The EPSRC and Huntsman Pigments are thanked for funding for this studentship via the UCL $\mathrm{M}^{3} S$ Doctoral Training Centre. We would like to thanks Drs. Graham Tizzard \& Peter Horton at the EPSRC National Crystallography Service for data set collection of 2a, $\mathbf{2 b}$ and 3. $^{[32]}$

Keywords: The Chloride Process • titanium dioxide • titanium(IV) chloride $\bullet$ ester.

References

[1] W. . Daoud, Self-Cleaning Materials and Surfaces A Nanotechnology Approach - Google Books, John Wiley \& Sons 2013.

[2] W. G.W.R, The Grove Encyclopedia of Materials and Techniques in Art, Oxford University Press, 2008.

[3] L. Börnstein, in Subvolume B 'II-VII-VII Compd. Semimagn. Compd. - Vol. 41 Semiconducors, 1999.

[4] J. Winkler, Titanium Dioxide, 2003 Applications of Reactive Metals: 1999 TMS Annual Meeting, San Diego, CA, February 28 - March 15, 1999, John Wiley \& Sons, 2013.

[7] B. Mishra, Ed. , 1999, DOI 10.1002/9781118788417.

[8] G. Buxbaum, Industrial Inorganic Pigments, Wiley-VCH Verlag $\mathrm{GmbH}$, Weinheim, Germany, 1998.

[9]

F. Fahnoe, J. A. Sturm, Purification of Titanium Tetrachloride by Distillation in the Presence of an Oil and the Use of an Inert Gas Purge, 1964, US $3156630 \mathrm{~A}$.
S. Xiong, Z. Yuan, Z. Yin, W. Yan, Hydrometallurgy 2012, 119-120, 16-22.

[11]

P. Cossee, J. Catal. 1964, 3, 80-88.

[12] A. J. Cross, C. W. Dunnill, I. P. Parkin, Chem. Vap. Depos. 2012 $18,133-139$

[13] G. K. Mor, K. Shankar, M. Paulose, O. K. Varghese, C. A. Grimes Nano. Lett. 2006, 6, 215-218.

[14] G. Maier, S. Ulrich, R. Boese, Tetrahedron Lett. 1987, 28, 45154516.

[15] M. Shao, J. Chin. Chem. Soc 2000, 3, 901-906.

[16] P. Sobota, S. Szafert, T. Lis, J. Organomet. Chem. 1992, 443, 8591.

[17] A. Bondi, J. Phys. Chem 27643BC, 3, 441-451.

[18] Y. Wu, Y. Ho, C. Lin, H. Gau, Inorg.Chem. 1996, 2, 5948-5952.

[19] D. a. Pennington, D. L. Hughes, M. Bochmann, S. J. Lancaster, Dalt. Trans. 2003, 2, 3480.

P. Sobota, Polyhedron 2013, 8, 2013-2016.

J. C. Gallucci, N. Kozmina, L. a. Paquette, Acta Crystallogr. Sect. C Cryst. Struct. Commun. 1998, 54, 1609-1612.

[22] Y. Huang, D. W. Stephan, Can. J. Chem 1995, 962, 956-962.

[23] M. Schormann, Acta Cryst. 2003, E59, M674-m675.

[24] H. Cui, Novel Oxovanadium Complexes with Alkoxy, Ketone, and Alcohol Ligands: Syntheses, Characterization and Catalysis, Technical University of Berlin, 2006.

[25] A. B. Pangborn, M. a. Giardello, R. H. Grubbs, R. K. Rosen, F. J. Timmers, Organometallics 1996, 15, 1518-1520.

R. C. T. Japan, CrystalClear-SM Expert $3 . .1$ b18, 2013

L. J. Farrugia, J. Appl. Cryst 2012, 54, 849-854.

F. H. Allen, O. Johnson, G. P. Shields, B. R. Smith, J. Appl. Cryst 2004, 37.

H. Dolomanov, O.V., Bourhis, L.J., Gildea, R.J, Howard, J.A.K. \& Puschmann, J. Appl. Cryst 2009, 42, 339-341.

G. Palatinus, L. \& Chapuis, J. Appl. Cryst 2007, 40, 786-790.

[31] G. M. Sheldrick, Acta Cryst. “ 2008, A64, 112-122.

[32] S. J. Coles, P. a. Gale, 2012, 683-689. 
WILEY-VCH

FULL PAPER 
Click here to download Additional Material - Author: Graphical Abstract.docx 
Click here to download Supporting Information: Compound 1a.cif 
Click here to download Supporting Information: Compound 1a.fcf 
Click here to download Supporting Information: Compound 1a_cifreport.pdf 
Click here to download Supporting Information: Compound 1b.cif 
Click here to download Supporting Information: Compound 1b.fcf 
Click here to download Supporting Information: Compound 1b_cifreport.pdf 
Click here to download Supporting Information: Compound 3.cif 
Click here to download Supporting Information: Compound 3.fcf 
Click here to download Supporting Information: Compound 3_cifreport.pdf 
Click here to download Supporting Information: XSTR0068-final.cif 
Click here to download Supporting Information: XSTR0068.fcf 
Click here to download Supporting Information: XSTR0068-final_cifreport.pdf 
Click here to download Supporting Information: XSTR0041_finalCEK.cif 
Click here to download Supporting Information: xstr0041.fcf 
Click here to download Supporting Information: XSTR0041_finalCEK.pdf 